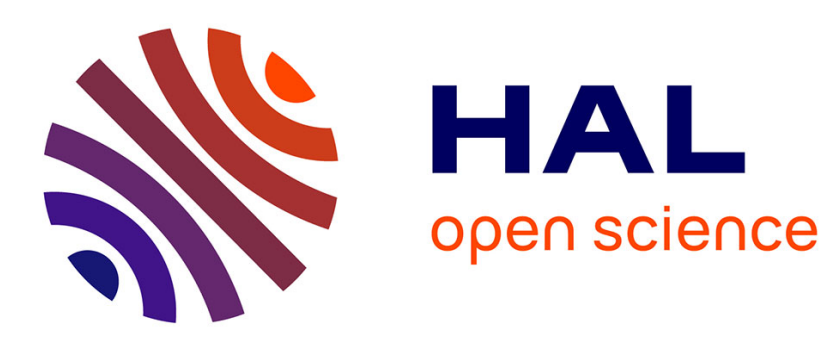

\title{
The posterior insular-opercular region and the search of a primary cortex for pain \\ Luis Garcia Larrea
}

\section{To cite this version:}

Luis Garcia Larrea. The posterior insular-opercular region and the search of a primary cortex for pain: the nociceptive cortex in humans. Neurophysiologie Clinique $=$ Clinical Neurophysiology, 2012, pp.2012;. inserm-00744512

\section{HAL Id: inserm-00744512 https://www.hal.inserm.fr/inserm-00744512}

Submitted on 23 Oct 2012

HAL is a multi-disciplinary open access archive for the deposit and dissemination of scientific research documents, whether they are published or not. The documents may come from teaching and research institutions in France or abroad, or from public or private research centers.
L'archive ouverte pluridisciplinaire HAL, est destinée au dépôt et à la diffusion de documents scientifiques de niveau recherche, publiés ou non, émanant des établissements d'enseignement et de recherche français ou étrangers, des laboratoires publics ou privés. 


\title{
REVIEW
}

\section{The posterior insular - opercular region and the search of a primary cortex for pain}

\author{
Luis Garcia-Larrea \\ Central Integration of Pain Laboratory, Centre for Neuroscience of Lyon \\ Inserm U1028 \& University Lyon 1, France
}

\begin{abstract}
To be considered specific for nociception, a cortical region should (a) have plausible connections with ascending nociceptive pathways; (b) be activated by noxious stimuli; (c) trigger nociceptive sensations if directly stimulated, and (d) tone down nociception when injured. In addition, lesions in this area should have a potential to develop neuropathic pain, as is the case of all lesions in nociceptive pathways. The single cortical region approaching these requirements in humans encompasses the suprasylvian posterior insula and its adjoining medial operculum (referred to as "PIMO" in this review). This region does not contain, however, solely nociceptive networks, but represents in primates the main sensory receiving area of the spinothalamic system, and as such contributes to the processing of thermo-sensory, nociceptive, $\mathrm{C}$-fibre tactile, and visceral input. Nociception (and, a fortiori, pain) should therefore not be considered as a separate sensory modality, but rather as one component of a global system subtending the most primitive forms of somatosensation. The medial opercular part of the PIMO is cytoarchitectonically and functionally distinct from the outer operculum containing the S2/PV sensory areas. Although a clear functional segregation of PIMO sub-areas has not yet been achieved, some preferential distribution has been described in humans: pain-related networks appear preferentially distributed within the posterior insula, and non-noxious thermal processing in the adjacent operculum. Thus, spinothalamic submodalities may be partially segregated in the PIMO, in analogy with the separate representation of dorsal column input from joint, muscle spindle and tactile afferents in S1. Specificity, however, may not wholly depend on ascending 'labelled lines' but also on cortical network properties driven by intrinsic and extrinsic circuitry. Given its particular anatomo-functional properties, thalamic connections, and tight relations with limbic and multisensory cortices, the PIMO region deserves to be considered as a third somatosensory region (S3) devoted to the processing of spinothalamic inputs.
\end{abstract}




\section{Résumé}

Pour être considérée spécifique de la nociception, une region corticale doit (a) recevoir des connexions ascendantes plausibles avec les voies nociceptives; (b) être activée par des stimuli nociceptifs; (c) évoquer des sensations nociceptives lorsqu'elle est directement stimulée, et (d) réduire la nociception si elle est lésée. Par ailleurs, les lésions d'une telle aire doivent avoir la potentialité de générer des douleurs neuropathiques, comme c'est le cas de toute lésion au sein des voies nociceptives. La seule aire corticale qui approche ces conditions est située chez l'Homme dans la région suprasylvienne, et comprend l'insula postérieure et l'opercule médial adjacent (qui dans cette revue sera appelée "PIMO", pour « Posterior-Insula-Medial-Operculum»). Ce territoire représente chez le primate l'aire sensorielle majeure de réception du système spinothalamique, et contribue par conséquent au traitement cortical des afférences non seulement nociceptives, mais aussi thermosensorielles et, dans une certaine mesure, tactiles et viscerales. La nociception (et a fortiori la douleur) ne doit donc pas être considérée comme une modalité sensorielle séparée, mais plutôt comme une des composantes d'un système global assurant les formes les plus primitives de sensation somatique. La partie operculaire du cortex PIMO, accolée à l'insula, peut être différenciée sur le plan cytoarchitectonique et fonctionnel de l'opercule latéral contenant les régions sensorielles S2 et PV. Bien qu'une ségrégation fonctionnelle du PIMO en sous-aires ne soit encore possible, une certaine distribution différentielle a été décrite chez l'Homme, les réseaux nociceptifs étant distribués préférentiellement au sein de l'insula postérieure et ceux voués au traitement de la chaleur nonnociceptive dans l'opercule suprasylvien adjacent. Il est donc probable que des sous-modalités spinothalamiques puissent être représentées de façon disjointe au sein de cette region, de manière analogue aux représentations disjointes des sous-modalités lemniscales au sein de S1. Cependant, la spécificité peut non seulement dépendre de "voies ascendantes dédiées", mais également de propriétés intrinsèques des réseaux corticaux, liées à leur connexions intrinsèques et extrinsèques. De par ses propriétés anatomo-functionnelles, ses connexions thalamiques et ses relations avec les cortex limbiques et multisensoriels, la region PIMO mérite à nos yeux d'être considérée comme une région somesthésique à part entière (S3) vouée au traitement des afférences spinothalamiques. 


\section{Introduction}

Knowledge on human cortical pain processing has received tremendous impetus in the last 20 years, through the use of functional brain imaging and electrophysiology combined with stimulus procedures that selectively activate nociceptive pathways. The concept of "Pain Matrix" (PM) arose in the early 90's to underscore that noxious stimuli do not activate a unique "pain centre" but a widespread network of brain regions (Talbot et al 1991, Jones et al 1992; Coghill et al 1994). Such network, supposedly responsible for the building of human pain sensation, consists of a basic core formed by the suprasylvian opercular area, the mid- and posterior insula and the mid-anterior cingulate cortex, which are systematically activated by noxious stimuli, but also a number of other regions including the primary sensory cortex, anterior insula, prefrontal and posterior parietal cortices, amygdala and hippocampus, detected in 40-80\% of studies (reviews in Peyron et al 2000, Garcia-Larrea et al 2003, Apkarian et al 2005, Stephenson \& Arneric 2008).

Being activated by external stimuli does not imply, however, being crucial for the expression of a given function (Price et al 1999). Pain is the conscious interpretation of nociceptive input and, as such, is influenced by memories, emotional and cognitive factors (Tracey \& Mantyh 2007, Tracey 2008). Accordingly, painful stimulation induces brain activations supporting functions connected with, but distinct from the process of pain perception proper, such as orienting reactions, memory encoding and anxious anticipation (Peyron et al 1999, Porro et al 2002, Valet et al 2004, reviews Lorenz and Garcia-Larrea 2003, Tracey \& Mantyh 2007, Valet et al 2010). Pain literature has sufficiently demonstrated that a number of elements within the PM are definitely not specific for pain, and can be triggered by any behaviourally relevant stimulus. Thus, while some investigators still consider the PM as a 'direct measure' of the actual pain experience (e.g. Borsook et al 2010), current trends assail the very concept of a specific pain-related network, claiming that most, if not all, the PM regions represent a non-specific salience-detection system for the body (Iannetti et al 2008, Iannetti and Mouraux 2010, review Legrain et al 2010, and see Legrain et al, this Volume).

While accepting that most of PM activity is nonspecific, it remains obvious that normal human beings clearly distinguish the sensory or non-sensory origin of an aversive perturbation. While social and moral suffering may activate regions that overlap with the PM (Eisenberger et al 2004, MacDonald \& Leary 2005, Kross et al 2011, Singer et al 2004), normal humans rarely confound moral sorrow with physical pain, which is identified as a sensation pertaining to the somatic modality, "caused by stimuli that threaten the integrity of the tissues". The detection of such stimuli by neural systems is called nociception (Perl 1998), a termed coined by Sherrington from latin capio: 
«to take » and noxa: "harmful". This paper will first explore the cortical regions and processes that subserve nociception, and which are necessary and sufficient to trigger in normal humans the complex and multifocal experience we call "pain". We shall first delineate the features that a cortical area should exhibit to aspire to a specific role in nociception, and show that the only region in humans exhibiting such features lies within the posterior granular insula and medial suprasylvian operculum -the "PIMO" cortex. We will suggest that nociceptive networks are part of a larger somatosensory area that can be defined as a thalamo-cortical projection of the spinothalamic system, whose functionality is not restricted to nociception but encompasses non-noxious thermal discrimination, C-fibre-mediated touch, visceral somatosensation, and sensory components of sexual pleasure. In this view, nociception should not be considered as a separate sensory modality, but rather as one component of a primitive but complete somatosensory system.

\section{The conditions to consider a cortical brain area as a nociceptive region}

A cortical region can be considered as containing nociceptive networks if: (a) there is anatomical evidence that the region receives projections from ascending systems conveying pain-related information; (b) the region is activated systematically by noxious stimuli; (c) direct stimulation of the region generates pain, and (d) lesions of this region entail specific nociceptive deficits. Furthermore, lesions of the region should be able to generate chronic neuropathic pain, which is a distinctive trait of lesions involving nociceptive pathways (Boivie 2006). In this section we shall explore these 5 conditions, and suggest that the region comprising the Posterior Insula and adjacent Medial Operculum (the "PIMO" area) contains networks that can be considered as specific for nociception.

\section{IIa. The spinothalamic system in primates projects to the PIMO}

The ascending system in the anterolateral spinal cord, or spinothalamic tract (STT), has long been known to be a major pathway for transmitting information on pain and temperature to the cerebral cortex. This system is not uniform, and comprises both direct axons transiting from the dorsal horn to the thalamus, and more complex pathways that activate the thalamus, or the cortex, only after synapses in the brainstem or hypothalamus (reviews in Willis 1985, Willis \& Westlund 1997, Craig 2003). The primate STT consists of anatomically and functionally differentiable components, which in monkeys originate largely from neurons in laminae I, V, and VII of the spinal cord (Apkarian and Hodge 1989). The axons of these spinal neurons terminate in multiple nuclei of the thalamus, mainly in its posterior part, with more than $90 \%$ concentrated in the ventral posterior complex (ventroposterolateral (VPL), ventroposteromedial (VPM), and ventroposteroinferior (VPI) nuclei) the central lateral (CL), the posterior-suprageniculate complex (Po-SG), and the caudal mediodorsal 
nucleus (MD). The posterior - supragenicular nuclear group is thought to include a subdivision termed "VMpo", receiving input essentially from lamina I (Craig 2004). Lamina I neurons project, however, to many other thalamic sites (Graziano and Jones 2004, Craig 2006), and the independent existence of VMpo has been questioned by other authors (e.g. Willis et al 2002, Graziano and Jones 2004).

In primates, the precise location and relative strength of input to the cortical spinothalamic targets could be defined only recently, using trans-synaptic viral transport from spinothalamic neurons in the cord (Dum et al 2009). Injection of herpes virus within dorsal horn laminae I, V and VII allowed the virus to be taken up by spinal cord neurons and transported rostrally to infect second-order thalamic neurons, then third-order cortical neurons receiving thalamic projections. While spinothalamic projections to primary somatosensory cortex, already known to be scarce (Casey and Morrow 1983, Gingold et al 1991), appeared to receive less than 5\% of the spinothalamic system input, the vast majority of spinothalamic cortical targets were found in (a) the posterior insular cortex (granular insula, $\sim 40 \%$ ), (b) the medial parietal operculum $(\sim 30 \%)$, and (c) the motor sections of the mid-cingulate cortex $(\sim 24 \%)$. Thus, the region comprising the posterior granular insula and the adjacent parietal operculum (PIMO) is the recipient of a vast majority (70\%) of spinothalamic cortical projections, and of almost $95 \%$ of all spinothalamic input to sensory cortices. Within the PIM, the posterior insula is connected principally with the thalamic posterior-suprageniculate complex (Po-SG), the VPI and oral-medial pulvinar nuclei (Mufson and Mesulam 1984; Friedman and Murray 1986), while major afferents to the parietal operculum arise from the VPI (Friedman and Murray 1986; Stevens et al 1993).

\section{IIb. The PIMO is activated by noxious stimuli (Fig 1A)}

The opercular - insular region is the area most consistently activated of the 'Pain Matrix', whether the latter is defined by functional imaging or electrophysiological methods (reviews Peyron et al 2000, Garcia-Larrea et al 2003, Kakigi et al 2005, Apkarian et al 2005, Tracey 2008). Unfortunately, haemodynamic imaging is unable to disclose which are the primary cortical recipients of afferents, nor is able to determine whether a given activated region is necessary or just contingent for the function considered. Indeed, contrary to anatomical studies targeting primary cortices (third-order neurons), functional imaging is largely dependent on fourth-order or longer connections developing during seconds to minutes after stimulation, thus mixing up early and late cortical responses. For instance, functional imaging of pain responses detected two independent foci of maximal significance, one in the posterior and the other in the anterior insula (Peyron et al 2000, Apkarian et al 2005, Tracey 2008), but only the former may be related to third-order thalamo-cortical projections (Dum et al 2009). Intracranial EEG recordings in humans have demonstrated that the PIMO region 
responds early and systematically to thermo-nociceptive laser stimuli (Lenz et al 1998, Frot et al 1999, 2001) (Figure 1A). Source modelling of the earliest brain responses to noxious thermal stimuli consistently shows activation in the opercular and insular regions, together with the mid-cingulate gyrus (Garcia-Larrea et al 2003), thus reflecting the STS projections determined by anterograde tracing in monkeys. The latencies of initial responses (150-180 ms) are very similar in the opercular and mid-cingulate areas (Schlereth et al 2003, Frot et al 2008), providing electrophysiological support in humans to the parallel spinothalamic projection to the PIMO and the motor cingulate (Dum et al 2009). The recruitment curves of medial opercular and posterior insular regions differ: the operculum responds to thermal pulses at perceptive threshold, but do not fully reflect the intensity scale (Chen et al 2006, Frot et al 2007). Conversely, the posterior insula tends to respond only when stimulus intensity has almost reached subjective pain levels (Frot et al 2007), and does not show saturation for intensities well above pain threshold (Börnhovd et al 2002) (Figure 2B).

\section{IIc. Opercular-insular stimulation can generate acute pain in humans (Fig. 1B)}

While reporting the results of fully awake craniotomy, Pereira et al (2005) described that neocortical manipulation of frontal, temporal, parietal or occiptal lobes was unpainful in 38 consecutive patients, whereas 10 out of 10 patients reported intense pain during vascular, arachnoid or cortical dissection of the PIMO area. In the same line, the only cortical sites where painful sensations were triggered by intracortical electric stimulation are within the opercular-insular cortex (Ostrowsky et al 2002, Mazzola et al 2006, 2012) (Figure 1B). Extensive reports on stimulation of other cortical regions of the PM, including the primary sensory cortex and lateral operculum (Penfield \& Jasper 1954, Richer et al 1993), supplementary motor area (Fried et al 1991), lateral frontal cortex and mid-anterior cingulate (Bancaud et al 1976, Chassagnon et al 2008) never mention pain responses. This issue was extensively investigated recently, by analysing the behavioural responses to more than 4000 intracortical stimulations covering the whole cortical mantle in 164 patients (Mazzola et al 2012). Subjective pain responses were obtained exclusively in the medial part of the parietal operculum and neighbouring posterior insula, with same incidence in both regions, whereas pain could not be elicited by stimulation of any other brain area. The stimulation of the PIMO region, however, generated pain in $10 \%$ of cases only, and thus differed from classical "primary sensory areas" where stimulation-driven sensory symptoms are virtually constant. As was the case with evoked potentials, different subregions showed different functional properties to focal stimulation, and both the size of projection of cutaneous fields and the incidence of painful (versus non-painful) responses were higher in the posterior insula than in the adjacent operculum (Mazzola et al 2006). Interestingly, Lenz et al (1995) reported the possibility of evoking "full pain experiences" by stimulating a thalamic 
region posterior to the main sensory nucleus (the human counterpart of VPL), at sites consistent with the posterior complex and nucleus ventrocaudalis parvocellularis, which do project to the PIMO (Mehler 1962, Wirth 1973).

Pain is a very rare symptom of epileptic seizures, reported in less than $1.5 \%$ of cases. Siegel et al (1999) described 8 patients, all of them with parietal origin, and discovered an opercular focus in two of them who underwent intracranial recordings. We recently reported purely painful epileptic seizures triggered by a very limited dysplasia in the posterior insula (Isnard et al 2011). Attacks originated in the posterior right insula and propagated with $80 \mathrm{~ms}$ delay to other areas of the PM, including the parietal operculum and the mid-cingulate gyrus. Stimulation of the insula, but not of other PM regions, induced pain identical to that of seizures, which could be successfully treated by millimetric thermo-coagulation of the insular epileptic focus. Together with the results of intracranial stimulation, these observations suggest that the 'experience' of pain can be triggered in the posterior insular cortex, but its development depends on the subsequent activation of a larger network of PM cortical areas.

\section{IId. Lesions in the PIMO entail selective nociceptive deficits (Fig 1, C-D)}

The first description of a selective loss of pain \& temperature sensation, with preserved proprioception and tactile discrimination probably comes from Dejerine \& Mouzon (1915), in a soldier who underwent a parietal gunshot injury during the 1st World War. Post-mortem neuropathological analysis of this syndrome was however not available until 1956, when Biemond [1956] reported two cases of selective loss of pain and temperature senses following posterior insular stroke; since then, a number of reports have confirmed that lesions involving the posterior insula and medial parietal operculum can give rise to selective pain \& temperature deficits (Obrador et al 1957, Bassetti et al 1993, Greenspan et al 1992, 1999; Horiuchi et al 1996, Birklein et al 2005, Kim 2007, Garcia-Larrea et al 2010), and this region is indeed the only where focal lesions have been described to selectively abolish or attenuate pain sensation (review in Garcia-Larrea 2012) (Figure 1CD). In contradistinction to this, lesions concerning exclusively the anterior insula were never associated with pain or temperature deficits in the detailed study of Greenspan et al (1999); those involving the lateral parietal operculum have been reported to produce global hypaesthesia, or a cheiro-oral syndrome with preserved pain sensation (Bogousslavsky et al 1991, Bowsher et al 2004), and lesions

disconnecting the anterior from the posterior insula were reported to dampen emotional reactions to pain, but preserve recognition of nociceptive stimuli (Berthier et al 1988).

\section{IIe. PIMO injury can lead to the development of central pain}


Lesions at any level of the pain pathways not only entail nociceptive hypaesthesia, but are also able to generate chronic neuropathic pain (Bowsher 2004, 2005; Boivie 1998, 2006). Combination of nociceptive hypaesthesia and spontaneous pain may occur at all levels of the neuraxis: in small-fibre neuropathies (Mendell and Sahenk 2003) as well as in spinal, brainstem or thalamic lesions involving the spinothalamic system (review Boivie 2006). In the cerebral cortex, the PIMO region is the only area where focal injury has been shown to induce central pain together with selective pain hypoesthesia. That central pain could emerge from operculo-insular lesions has been known for decades (e.g. Biemond 1956, Bowsher et al 2004, Kim 2007), but individualisation of 'parasylvian pain' as a distinct central pain syndrome is recent (Garcia-Larrea et al 2010). Central pain associated with selective nociceptive hypaesthesia is an exclusive feature of lesions in ascending pain pathways, and this underscores the role of the PIMO as a receiving area of ascending nociceptive projections (see IIa).

\section{The PIMO area is more than a primary sensory cortex for pain}

The identified capacity of the PIMO region to process pain-related stimuli has lead some investigators to claim that this region represents a "primary area for pain". However, the PIMO is involved in the processing of other, miscellaneous sensory inputs, and during the last 15 years the human operculo-insular region has been considered to contain primary sensory networks for a number of sensibilities including thermo-sensation, emotional touch, mechanical and heat pain, or 'protopathic feelings subserving interoception'. While each of these claims may be founded on sound experimental data, none of them captures the whole functional complexity of the PIMO region.

\section{IIIa. The PIMO as a thermo-sensory area.}

Thermal stimuli significantly activate the PIMO (Coghill et al 1999, Craig et al 2000, Maihofner et al 2002, Hua et al 2005), and haemodynamic activity within this region shows linear correlations with both increasing (Coghill et al 1999) and decreasing temperature changes (Craig et al 2000). Pain and temperature being closely interconnected sensations, it is not surprising that both be encoded by closely-lying brain networks. Thus, even minute focal lesions in the PIMO can suppress both thermal and pain perceptions (Greenspan et al 1999, Kim 2007, Garcia-Larrea et al 2010; see Figure 1, C-D), and stimulation of the operculo-insular region in awake humans elicits thermal warm and painful heat sensations in a comparable proportion of cases (Ostrowsky et al 2002, Mazzola et al 2006, 2012). Noteworthy, stimuli evoking non-painful warm and cold tended to concentrate in the medial operculum, while those yielding pain predominated in the posterior dorsal insula (Figure 2, and see Mazzola et al 2006, 2011). This is in accordance with studies of evoked potentials to thermal laser 
stimuli, where the opercular region was able to encode low levels of thermal change, (Chen et al 2006, Frot et al 2007) whereas the posterior insula tended to respond only when thermal stimuli almost had reached the subjective pain threshold (Frot et al 2007).

\section{IIIb. Mechano-sensation in the PIMO}

The PIMO region is involved in different types of mechano-sensation too. The pain reported after opercular-insular stimulation is often non-thermal in nature, and described as electric-like shocks, strong "pins and needles", crushing sensations or cramps in more than 30\% of cases (Mazzola et al 2006). Moreover, almost $50 \%$ of stimuli in the PIMO evoke non-painful and non-thermal sensations, mainly cutaneous paresthesiae (Ostrowsky et al 2002, Mazzola et al 2006, 2009). Patients with focal lesions in the PIMO commonly have strong deficits in mechanical pain, and as early as 1956 Biemond reported patients with operculo-insular injury being "hardly troubled by strong pressure" (Biemond, 1956, p. 233). More recently Greenspan et al (1999) observed that pain deficits from opercular lesions could in some patients be exclusively mechanical, with "not even a slight difference in beat pain threshold or cold pain tolerance". High-resolution fMRI during specifically mechanical pain (prick) demonstrated a significant focus of posterior insular activation, the location of which was not different from those obtained using thermal stimuli (Baumgartner et al 2010). Both in monkey and man, some neurons in the lateral thalamus are responsive to noxious mechanical, but not to noxious thermal stimuli (Kenshalo et al 1980, Chung et al 1986, Lenz et al 1993, 1994).

Mechano-sensation in the PIMO is not limited to pain. Non-painful tingling, light touch, feeling of pulsation, vibration, or slight electric current were produced by direct stimulation of the medial parietal operculum and the posterior insula in no less than 35\% of cases (Mazzola et al 2006, 2012), thus in a greater proportion than any pain or temperature sensations. Single-unit recordings in monkeys show responses to mechanical activation, including gentle hair deflection, in the dorsal posterior insula (Robinson and Burton 1980, Schneider et al. 1993, Coq et al. 2004), and injury to the PIMO in humans often modifies significantly the tactile thresholds (Schmahmann et al 1992, Greenspan et al 1992, 1999, Garcia-Larrea et al 2010). A dual tactile innervation exists in humans, based respectively on fast-conducting $\mathrm{A} \beta$ fibres and slow-conducting $\mathrm{C}$-afferents responding to light touch. C-fibre tactile sensations are carried by the spinothalamic tract via synapses in lamina I (Craig 2002) and layers III-V (Zhang et al 1991), and may be relayed to the posterior insula by the thalamic posterior (Po) and suprageniculate-limitans nuclei (Apkarian and Shi 1994). In monkeys, neurons in the posterior granular insula often responded to gentle hair deflection within receptive fields covering large areas of the body (Robinson and Burton 1980), and in patients totally deprived of A $\beta$ fibres, stimulation of C-tactile afferents activated selectively the posterior insula, but not the primary somatosensory cortex or the lateral operculum (Olausson et al 2002, 2008). Comparison of tactile 
activation of the forearm (where $\mathrm{A} \beta$ and $\mathrm{C}$-tactile afferents coexist) and the palm (devoid of $\mathrm{C}$-tactile afferents) suggested that the most posterior part of the insula is a selective target for C-driven touch afferents (Olausson et al 2002, Björnsdotter et al 2009). The insular activation by C-mediated touch increased at low stroking velocities consistent with caresses (Morrison et al 2011), and produced "a faint sensation of pleasant touch" in one patient devoid of A $\beta$ fibres (Olausson et al 2002). Based on these observations, C-driven tact has been considered the specific support for 'emotional', 'sensual' or 'social' touch (Olausson et al 2001, 2010, Craig 2003, Morison et al 2011). However, a strict relation between $\mathrm{C}$-tactile afferents and emotional aspects of tact cannot be derived confidently: For instance, C-afferents can evoke tactile sensations devoid of any particular pleasure, such as those elicited by punctate Von Frey filaments (Cole et al 2006), and direct stimulation of the posterior insula, where these afferents project, evokes tactile sensations of pulsation, vibration or electric current, which are not described as particularly pleasant (Mazzola et al 2006, 2009). Furthermore, "emotional tact" is not specifically triggered by C-afferents: tickle can be induced after complete interruption of the spinothalamic tracts (Nathan, 1990), and sensual tactile sensations can be derived from regions devoid of C-tactile fibres, such as the hand's palm (Löken et al 2012), as beautifully described by Honoré de Balzac ("the kiss she allowed me to lay upon her hand, [...] only the back and never the palm, as though she drew the line of sensual emotions there") (De Balzac 1836). Thus, although the notion of a C-driven tactile system projecting to the PIMO can be avowed with confidence, the pleasant character of such sensations appears essentially context-dependent.

Itching, or the "sensation associated with the desire to scratch" is another non-thermal feeling involving the PIMO region. Peripheral itching depends on activation of thin afferents, both C (Mochizuki et al 2008) and A-delta (Ringkamp et al 2011), and is transmitted rostrally via the spinothalamic tract (Jeffry et al 2011). Histaminergic and nonhistaminergic itching seem to involve different STT channels (Davidson et al 2007, Papoiu et al 2011) but all STT neurons responding to itching also respond to mechanical pain, and two thirds to thermal heat (Davidson et al 2007, 2010). In humans, anterolateral cordotomy simultaneously abolish itch and pain (Nathan 1990), patients with congenital insensitivity to pain also lack itch sensations (Indo 2010), and the same neurological illnesses that cause neuropathic pain can also, or instead, cause neuropathic itch (Seo et al 2009, review Oaklander 2011). Such intimate relations between itch and pain make the existence of itchrelated projections to the PIMO highly plausible, and this is supported by functional imaging studies in humans. Most fMRI and EEG/MEG studies have shown activations within the PIMO areas (posterior insula, medial operculum or both: Drzezga et al 2001, Herde et al 2007, Leknes et al 2007, Mochizuki et al, 2007, 2009; Yosipovitch et al 2008, Vierow et al 2009). Studies in which these regions were not activated by itching (e.g. Hsieh et al 1994, Darsow et al 2000, Mochizuki et al 2003) 
mostly tested lower concentrations of histamine (discussed in Leknes et al 2007) or used PET-scan to determine activated regions, with possible lack of sensitivity to small activation volumes. Studies comparing directly brain responses to pain and itching are scarce and mostly due to the Kyoto group: in the medial operculum, ACC and (especially) in the thalamus the BOLD response to pain was more intense and long-lasting for pain than for itch, while surprisingly the reverse was true in the posterior insula (Mochizuki et al 2007, see their Fig 3). Despite close association between itch and pain, the two subjective experiences are subjectively distinct and even inversely related: clear instances of this are the reduction of itching by nociceptive scratching, and the emergence of itch as a side effect of analgesic opioids. Also, itching sensations have never been described following intracranial stimulation of neither the posterior insular nor the medial operculum.

\section{IIIc. Interoception and the PIMO}

As defined by Sherrington, interoception refers to "stimuli that originate inside the body", and comprises all sensations coming from the gastrointestinal, urinary or reproductive tracts, circulatory or respiratory systems. This generic term includes such dissimilar feelings as hunger and thirst, air hunger, sexual arousal, orgasm, nausea, or urge to void. Although it has been proposed to redefine interoception as including "temperature, pain, itch and other somatic feelings" (Craig 2002), such allinclusive definition contradicts the very notion of internalness (i.e. "coming or acting from within" Collins ${ }^{\circledR}$ ), and does not adequately replace the classical views (see also Lenz et al 2004).

Visceral afferents reach the CNS via two pathways, involving respectively the vagus and the splanchnic nerves. Vagal afferents reach the nucleus of the solitary tract (NST), itself projecting to a large number of central targets in the brainstem, hypothalamus and limbic forebrain (amygdala and anterior insula) (Jänig 1996; Rinaman 2010). It is likely that most visceral vagal inputs bypass sensory areas and never reach consciousness (Jänig 1996), but can lead to cortical arousal and are associated to regulatory reflexes inducing conscious sensations, such as nausea (Cameron 2001). The second visceral path reaches via the splanchnic nerves the dorsal horn, where there is substantial convergence with exteroceptive afferents in laminae I, V and X (Tattersall \& Cervero 1986). Visceral afferents extend over more cord segments than corresponding exteroceptive C-afferents, and only 2$5 \%$ of spinal afferents with bodies in the root ganglia come from the viscera (Jänig \& Morrison 1986), explaining the poor spatial localisation of visceral sensation. Visceral afferents ascend both within the STT and a post-synaptic dorsal column pathway (Willis et al 1999).

A review of 54 functional imaging studies found substantial overlap between the projections of visceral and exteroceptive inputs, and considered the posterior insula as "the primary projection area for visceral afferent information" (Mayer et al 2009). In contrast with this, interoceptive units in 
monkeys are found in the mid-insula rather than its posterior part (Zhang et al. 1998, 1999), and in the recent meta-analysis from Kurth et al (2010) the region specific to human interoceptive processing was not in the posterior but in the central insula. Also, interoceptive sensations such as air hunger, listening to one's own heartbeat or urge to void tend to activate the central and anterior insula (Banzett et al 2000, Kuhtz-Buschbeck et al 2005), and direct electrical stimulation in humans entails visceral feelings at locations clearly anterior relative to those eliciting general somatosensory or pain sensations (Isnard et al 2004, Stephani et al 2011, Isnard personal communication). The assertion that the posterior insula constitutes a primary interoceptive image of homeostatic afferents (Craig 2002) is therefore inconsistent with the evidence reviewed above. One hypothesis to be confirmed is that anterior and mid-insular activity would depend upon vagal afferents, by-passing somatosensory cortices and projecting via the NST to anterior insular segments (Rinaman 2010), while the (anterior portion of) posterior granular insula may represent one target of viscero-somatic input carried exclusively by splanchnic pathways.

While the insula is commonly activated by interoceptive stimuli, it is noticeable that the activation in opercular areas most often does not reach significance (e.g. Lu et al 2004). Also, visceral perceptions in humans are clearly more prevalent to insular than opercular stimulation (Mazzola et al 2006, 2009), and in rat and monkey the percentage of neurons responding to interoceptive changes in the medial parietal operculum was much smaller than in the adjacent mid-insula (Zhang et al 1998, 1999). There may exist, therefore, a functional segregation within posterior insula and medial operculum, which reminds that observed in its responsiveness to warm and hot stimuli (see Section IIIa).

\section{The PIMO as a distinct somatosensory area}

Based on anatomical plausibility, activation by appropriate stimuli, lesion-induced deficits, and stimulation-induced perceptions, the previous sections illustrate how the PIMO region contains networks specific for nociception, but also for a number of non-noxious sensations including heat,

cold, touch, itch, and visceral feelings. Since each of these somatosensory attributes is represented in this region, the PIMO appears as the cortical target projection of a distinct system for somatosensory processing.

The modalities of somatosensation converging in the PIMO have several points in common. First, the neural machinery ensuring their transmission relies, with little exception, upon thin $A \delta$ and C fibres in the periphery, and the spinothalamic system (STS) in the spinal cord ${ }^{1}$. Accordingly, 
sensory modalities processed in the PIMO do not cover the whole spectrum of somatosensory abilities: proprioception, graphesthesia or stereognosis, transmitted by the medial lemniscal pathways, are not processed in the PIMO (Kim 2007). Second, the outer, most lateral portions of the parietal operculum appear to be excluded from this somatosensory input. The spinothalamic system targets the inner operculum, rather than its outer part (e.g. Figure 5 in Dum et al 2009), and although noxious stimuli may entail haemodynamic activation of the lateral operculum too (Peyron et al 2000, Apkarian et al 2005, Mazzola et al 2012), such stimuli most often imply simultaneous tactile input, which vigorously activates this area. Lesions restricted to the lateral operculum do not entail selective spinothalamic symptoms (Bogousslavsky et al 1991, Bowsher et al 2004), while lesions affecting the PIMO generate deficits identical to those encountered after injury to spinothalamic pathways (se above, section IId). C-driven tact and itching, which consistently activate the PIMO, spare the lateral operculum (Olausson et al 2002, 2008; Björnsdotter et al 2009, Drzezga et al 2001, Herde et al 2007, Leknes et al 2007, Mochizuki et al 2007). Conversely, A $\beta$ tactile stimuli, which somatotopically activate the lateral operculum, hardly activate its medial part (Eickhoff et al 2007).

Evidence for different functional areas within the parietal operculum of mammals, especially primates, has accumulated since the 1990's. This lead to functional segmentation and redefinition of a cortex that had sometimes been loosely labelled "S2" (Krubitzer and Kaas 1990, Krubitzer and Calford 1992, Krubitzer et al 1995, Burton et al 1995, Qi et al 2002, review in Kaas and Collins 2003), and four distinct areas with their own somatotopic representations have been described in monkeys, two in the lateral operculum (S2 proper and Parietal Ventral area, or PV), and two in its medial part (Ventral Somatosensory areas caudal and rostral, VSc and VSr) (Coq et al 2004, Kaas \& Colllins 2003). In humans, histological examination of 10 post-mortem brains also identified four distinct opercular regions, labelled OP1 to OP4 by Eickhoff and colleagues (2006a,b). Two of these areas are lateral (OP1 and OP4) and would correspond to S2 proper and the parietal ventral area PV (see Figure 4 in Eickhoff et al 2006b), while the two medial regions, contiguous with the insula (OP2 and OP3), appear as human equivalents of the ventral somatosensory area (VS), retroinsular and insular-opercular vestibular cortex (Eickhoff et al 2006c, 2007; Gallay et al 2012). There is an intimate macro- and microscopic relationship between the medial operculum and the dorsal insula: not only the medial opercular areas extend into the insular domain, beyond the circular sulcus in monkeys and humans (Kurth et al 2010, Gallay et al 2012), but also the somatotopic representation in inner operculum (VS areas) follows an antero-posterior axis similar to that in the posterior insula, and different from the medio-lateral somatotopy in lateral opercular S2/PV (Krubitzer et al 1995,

Exceptions to this rule are nociceptors with conduction velocity in the low A $\beta$ range (Djouhri \& Lawson 2004) and post-synaptic visceral afferents in the dorsal-columns (Willis et al 1999) 
Brooks et al 2005, Mazzola et al 2009, see Fig 15 in Coq et al 2004). Such relation is also neurochemical and highlighted by the study of human opioid receptors, which shows a medio-lateral gradient with highest opioid receptor density in the insula and inner operculum, which decreases laterally (Baumgartner et al 2006). Therefore, the innermost operculum can be segregated histologically, somatotopically and neurochemically from the more lateral S2/PV areas, and appears functionally associated with the posterior insula, of which it forms the dorsal border. The assertion that the primate posterior insular cortex contains "a sensory representation of small-diameter afferent activity" (Craig 2002), while generally correct, should therefore include the medial operculum, which contains a representation of thin afferents too (Dum et al 2009). Interestingly, the dorsal insular region, suggested as a specific recipient of lamina I projections (Craig 1995), has been recently shown to extend into the medial operculum too, as suggested by higher myelination and enhanced staining for parvalbumin, SMI-32 and acethylcolinesterase (Gallay et al 2012). Together, the posterior insula and innermost parietal operculum behave as a somatosensory area on its own. Given its anatomical and functional differences from the S1 and S2 cortices, this region might be conceptualised as a genuine 'third somatosensory area' (S3).

\section{The PIMO as cortical processor of primitive somatosensory attributes}

From a phylogenetic perspective, several lines of evidence suggest that the sensory attributes handled in the PIMO are among the oldest somatosensory capabilities of living organisms. The most conspicuous PIMO role is the processing of rudimentary mechanical, thermal and noxious inputs, which are essential for survival and must have developed before discriminative tactile abilities, stereognosis or proprioception appeared (Smith and Lewin 2009). Invertebrates (annelida) such as the leech possess segmental ganglia containing touch, pressure and noxious cells (Nicholls and Baylor 1968, Pastor et al 1996). The latter respond to strong mechanical, chemical or thermal stimuli, and lower their threshold for repeated activation, just as mammalian nociceptors. 'Wide dynamic range' neurons responding to both weak and noxious stimulation are observed in mollusca such as Aplyssia (Walters et al 1983), and all these primitive senses in invertebrates are conveyed by unmyelinated fibres. In vertebrates, the evolution pursues from an unmyelinated nervous system in the sea lamprey (which displays both mechanical and heat sensitivity) to fishes, where myelinated nociceptors are first observed (Smith \& Lewin 2009).

Study of the ascending pathways also supports the old phylogenetic history of spinothalamic system precursors. Paleospinothalamic connections have not been described in teleost fishes (Sneddon 2009), while they might exist in some amphibians and not in others (e.g. salamander $v s$. 
frog; Herrick 1948, Kevetter \& Willis 1984). In the masurpial phallanger the ascending nociceptive system is interrupted in the brainstem (Clezy et al 1961) whereas in the Opossum 2\% of anterolateral fibres reach the thalamus (Mehler 1969), and the proportion of direct fibres reaching the thalamic VPL/VPI increases with phylogenetic progression (Mehler 1969). Thus, a somatosensory system based on unmyelinated or thinly myelinated inputs appears to have preceded that of large diameter myelinated fibres. Physical disjointing of their respective cortical targets may have existed since the beginning, or develop in parallel with the progressive "operculation" of the insular cortex, which is situated entirely on the hemisphere surface in hedgehogs and rabbits, partly covered by adjacent cortical formations in carnivores and prosimians, to become totally "operculated" only in primates and cetaceans (Brodmann 1909, Russo et al 2009, Nieuwenhuys 2012). The insula is a phylogenetically conservative telencephalic part that has preserved most of its functions in species ranging from the Rodentia to the Primates (Russo et al 2008, Nieuwenhuys 2012), and may have undergone the operculation process while keeping its main functions, including that of cortical recipient of somatosensory input. Even the oldest mammals studied are provided of 5 somatosensory areas (Kaas 1995), but the intrinsic evolution of these regions may have been largely independent: for instance, mirroring of the complete S1 body representation is a feature of anthropoid primates, while virtually all extant mammals have a complete S2 sensory region (Johnson et al 1994). Different somatosensory areas appear to have operated first as "parallel systems", and thalamocortical somatosensory projections present indeed a parallel arrangement in carnivores and most prosimians, in which inactivation of one area does not abolish activity in the other (Zhang et al 1996). A serial somatosensory processing develops only in simians, in whom removal of S1 denervates S2 (Garraghty et al 91, review in Mountcastle 2005), suggesting new connectivity patterns to form a cascaded cortico-limbic somatosensory pathway involved in recognition and recall (Mountcastle 2005).

\section{Sub-areas within the PIMO - multiple primary cortices?}

At millimetric level, different somatic representations largely overlap in the PIMO, and lesions restricted to this area tend to simultaneously alter thermal, tactile and pain thresholds (Greenspan et al 1999, Birklein et al 2005, Kim 2007, Garcia-Larrea et al 2010). In monkeys, a same neuron in the posterior insula could respond to noxious and non-noxious stimuli (Robinson and Burton 1980), and in at least one human case electrical stimulation in the insula generated first a cold sensation and later a painful electric-like shock (Ostrowsky et al 2002). Despite such obvious convergence, both intracortical stimulation and intracortical evoked potentials in humans suggest some modal segregation, whereby non-noxious thermal encoding tends to concentrate in the medial operculum 
whereas pain and viscero-sensitive responses predominate in the dorsal posterior insula (Mazzola et al 2006, Frot et al 2007) (Fig 2). Segregation is not solely cortical: a study of 63 patients with lesions of ascending spinothalamic pathways found separable deficits of touch, sharpness, innocuous warmth/cold, mechanical and heat pain, suggesting partially independent representation of these sub-modalities at all levels (Bowsher 2005). Functional parting in insula and operculum would bear resemblance to that in S1, where neurons of different sub-modalities are distributed differentially in post-central areas 3a, 3b, 1 and 2. Slowly and quickly adapting neurons are preferentially restricted to areas $3 \mathrm{~b}$ and 1 , respectively, while input from muscle spindle afferents reaches area $3 \mathrm{a}$, and joint receptor inputs are mainly projected to area 2 on the top of the gyrus. Noteworthy, the concept of a "S1" cortex has survived despite the fact that area 3b may be considered as a "primary cortex" for discriminative tact, area 2 for joint position sense, and area $3 \mathrm{a}$ for muscle stretch perception (Desmedt and Ozaki 1991, Jones 1983, Kaas \& Collins 2003, Kutoku et al 2007, Mountcastle 2005). The "S1" concept survived because it reflects a functional unit of essentially tactile processing receiving input from the dorsal column - medial lemniscus system through the ventrocaudal thalamus. In this line, the PIMO area corresponds to another functional unit receiving input from spinothalamic channels through thalamic relays different from, and posterior to, the VPL/VPM complex. As in S1, it might be possible to separate within the PIMO different functional subareas, in particular a more internal part concerned predominantly with noxious stimuli (and perhaps C-tactile and viscerosomatic), and a more external, opercular part, where non-noxious thermal and pressure stimuli are preferentially processed. However, the whole system appears to share a common functional role as the first sensory cortical recipient of the most primitive somatic inputs (Kim 2007). Between the PIMO and S1, the lateral operculum containing the S2/VP areas appears to participate from both systems, receiving both dorsal column - lemniscal afferents and spinothalamic input via the VPI (Pollin and Albé-Fessard 1979, Dykes et al 1981, Dum et al 2009).

\section{Labelled lines versus network specialisation}

Segregation of functional abilities lends support to the hypothesis that "labelled lines" with partially independent processing machineries may sustain specific sub-modalities, from the periphery to the cortex. However, while labelled lines in the ST system have received abundant anatomical support (e.g. Andrew and Craig 2002, Craig 2003, 2004b 2006, Bowsher 2005), they show obvious limits too. Recording studies in monkeys failed to discover differences between the response properties of individual neurons in the posterior granular insula and the adjacent operculum (Robinson and Burton 1980, Schneider et al 1993; Zhang et al., 1999, comment in Dum et al 2009). Neurons responding to different sub-modalities are evenly distributed in the opercular-insular region (Robinson and Burton 
1980), and there is much evidence of convergence of different sub-modalities of autonomic and somatosensory input in the insula, with for example neurons responding to both baroreceptor and nociceptive activation (Zhang et al 1999). Thalamic units projecting to the insula receive both autonomic and nociceptive input (Zhang et al 1997), and STT neurons responding to itching in primates also respond to mechanical pain and thermal heat (Davidson et al 2007, 2010). We may propose that segregation of sub-modalities in sensory cortices, including the PIMO, may not rely on the intrinsic properties of individual neurons, but rather on stimulus timing and biophysical network properties. Thus, it has been suggested that discriminating noxious from non-noxious stimuli is based on temporal network dynamics and reverberation within thalamocortical loops (Wang et al 2008), and the most conspicuous differences between itch and pain-related activations concerned timing and duration of thalamic activity (Mochizuki et al 2007). Also, the much more extended connectivity patterns in the posterior insula than the opercular region may sustain differences in their regional responsiveness, the massive amount of afferent input to the insula entailing a greater background activity than in the adjoining operculum. This should hamper the precise encoding of low-energy stimuli barely emerging from background noise, and may explain why posterior insula networks are biased toward nociception (Frot et al 2007), despite the fact that approximately $70 \%$ of primate insular neurons can respond to non-noxious somatic inputs too (Robinson and Burton 1980). Thus, the afferent signals generated in the periphery are not obligatorily 'carried through' to the cerebral cortex in labelled-line systems (see comment in Jänig 1996); the cortex can create segregation by its internal properties, and network activity rather than intrinsic attributes of individual neurons can tune a region toward a functional significance or another.

\section{Conclusion.}

Sensory experiences are the emergent result of intensively connected networks, and cannot be 'contained' in a discrete cortical area. The search of a "primary cortex for pain" leads to a region comprising the posterior granular insula and its adjacent medial operculum, which are not solely devoted to nociception but also to the processing of somatosensory attributes transmitted by the spinothalamic system, of which they constitute the main cortical projection. Nociception can be triggered by virtually all kinds of spinothalamic input, be it cold, heat, pressure or distension, when a potentially harmful deviance from homeostasis is reached. At a difference with other sensations also signalling homeostatic deviances, such as thirst or hunger, nociception implies urgency, and the need of an immediate reaction -commonly escape. Each of the somatosensory cortical areas, by virtue of its unique pattern of extrinsic connections and intrinsic operations, contributes "a particular attribute to the final perceptual image" (Mountcastle 2005). Given its particular anatomo-functional properties, thalamic connections, and tight relations with limbic and multisensory cortices, the PIMO 
would deserve to be considered as a third somatosensory region (S3) contributing to the spinothalamic attributes to this final perceptual experience. 


\section{References}

1. Andrew D, Craig AD. Quantitative responses of spinothalamic lamina I neurones to graded mechanical stimulation in the cat. J Physiol. 2002;545:913-31.

2. Apkarian AV, Hodge CJ. Primate spinothalamic pathways: I. A quantitative study of the cells of origin of the spinothalamic pathway. J Comp Neurol 1989; 288:447-73.

3. Apkarian AV, Shi T. Squirrel monkey lateral thalamus. I. Somatic nociresponsive neurons and their relation to spinothalamic terminals. J Neurosci. 1994;14: 6779-95.

4. Apkarian AV, Bushnell MC, Treede RD, Zubieta JK. Human brain mechanisms of pain perception and regulation in health and disease. Eur J Pain. 2005;9(4):463-84.

5. Bancaud J, Talairach J, Geier S, Bonis A, Trottier S, Manrique M. Behavioral manifestations induced by electric stimulation of the anterior cingulate gyrus in man. Rev Neurol 1976;132:70524.

6. Bassetti C, Bogousslavsky J, Regli F.Sensory syndromes in parietal stroke. Neurology. 1993; 43: 1942-49.

7. Baumgärtner U, Tiede W, Treede RD, Craig AD. Laser-evoked potentials are graded and somatotopically organized anteroposteriorly in the operculoinsular cortex of anesthetized monkeys. J Neurophysiol. 2006;96:2802-8.

8. Baumgärtner U, Buchholz HG, Bellosevich A, Magerl W, Siessmeier T, Rolke R, Höhnemann S, Piel M, Rösch F, Wester HJ, Henriksen G, Stoeter P, Bartenstein P, Treede RD, Schreckenberger M. High opiate receptor binding potential in the human lateral pain system. Neuroimage 2006;30:692-9.

9. Baumgärtner U, Iannetti GD, Zambreanu L, Stoeter P, Treede RD, Tracey I. Multiple somatotopic representations of heat and mechanical pain in the operculo-insular cortex: a highresolution fMRI study. J Neurophysiol.2010; 104: 2863-2872.

10. Beckers G, Zeki S. The consequences of inactivating areas V1 and V5 on visual motion perception. Brain 1995;118: 49-60.

11. Berthier M, Starkstein S, Leiguarda R. Asymbolia for pain: a sensory-limbic disconnection syndrome. Ann Neurol. 1988;24:41-9

12. Biemond A. The conduction of pain above the level of the thalamus opticus. Arch Neurol Psychiatry 1956; 75: 231-44. 
13. Birklein F, Rolke R, Muller-Forell, W. Isolated insular infarction eliminates contralateral cold, cold pain, and pinprick perception. Neurology 2005; 65:1381.

14. Björnsdotter M, Löken L, Olausson H, Vallbo A, Wessberg J. Somatotopic organization of gentle touch processing in the posterior insular cortex. J. Neurosci. 2009; 29: 9314-9320

15. Boivie J. Central post-stroke pain. In: Cervero F, Jenssen T, editors. Handbook of clinical neurology, Vol. 81 (3rd series), Ch. 48. Elsevier, 2006. pp 715-30.

16. Boivie J, Leijon G, Johansson I. Central post-stroke pain--a study of the mechanisms through analyses of the sensory abnormalities. Pain 1989;37:173-185.

17. Borsook, D., Sava, S., Becerra, L., 2010. The pain imaging revolution: advancing pain into the 21 st century. Neuroscientist 16, 171-185.

18. Bogousslavsky J, Dizerens K, Regli F, Despland PA. Opercular cheiro-oral syndrome. Arch Neurol. 1991;48: 658-61.

19. Börnhovd K, Quante M, Glauche V, Bromm B, Weiller C, Buchel C. Painful stimuli evoke different stimulus-response functions in the amygdala, prefrontal, insula and somatosensory cortex: a single-trial fMRI study. Brain 2002;125: 1326-36

20. Bowsher D. Representation of somatosensory modalities in pathways ascending from the spinal anterolateral funiculus to the thalamus demonstrated by lesions in man. Eur Neurol. 2005;54:14-22.

21. Bowsher D, Brooks J, Enevoldson P. Central representation of somatic sensations in the parietal operculum (S2) and insula. Eur Neurol 2004; 52: 211-25

22. Brodmann K. Vergleichende Lokalisationslehre der Grosshirninde in ihren Prinzipien dargestellt und Grund des Zellenbaues. Leipzig, 1909, J.A. Barth

23. Brooks JCW, Zambreanu L, Godinez A, Craig AD, Tracey I. Somatotopic organisation of the human insula to painful heat studied with high resolution functional imaging. NeuroImage 2005;27:201-9.

24. Burton H, Videen TO, Raichle ME. Tactile-vibration-activated foci in insular and parietalopercular cortex studied with positron emission tomography: mapping the second somatosensory area in humans. Somatosens Mot Res. 1993;10:297-308.

25. Burton H, Fabri M, Alloway K. Cortical areas within the lateral sulcus connected to cutaneous representations in areas $3 \mathrm{~b}$ and 1 : a revised interpretation of the second somatosensory area in macaque monkeys. J Comp Neurol 1995;355:539-62. 
26. Cameron OG. Interoception: The Inside Story-A Model for Psychosomatic Processes. Psychosomatic Medicine 2001; 63:697-710.

27. Casey KL, Morrow TJ. Ventral posterior thalamic neurons differentially responsive to noxious stimulation of the awake monkey. Science 1983;221: 675-7

28. Chassagnon S, Minotti L, Kremer S, Hoffmann D, Kahane P. Somatosensory, motor, and reaching/grasping responses to direct electrical stimulation of the human cingulate motor areas. J Neurosurg 2008;109:593-604.

29. Chen WT, Yuan RY, Shih YH, Yeh TC, Hung DL, Wu ZA, Ho LT, Lin YY. Neuromagnetic S2 responses do not fully reflect pain scale. Neuroimage 2006; 31: 670-6.

30. Chung JM, Lee KH, Surmeier DJ, Sorkin LS, Kim J, Willis WD. Response characteristics of neurons in the ventral posterior lateral nucleus of the monkey thalamus. J Neurophysiol. 1986;56:370-90.

31. Clascá F, Llamas A, Reinoso-Suárez F. Insular cortex and neighboring fields in the cat: a redefinition based on cortical microarchitecture and connections with the thalamus. J Comp Neurol. 1997;384:456-82.

32. Clascá F, Llamas A, Reinoso-Suárez F. Cortical connections of the insular and adjacent parietotemporal fields in the cat. Cereb Cortex 2000;10:371-99.

33. Clemo HR, Stein BE. Organization of a fourth somatosensory area of cortex in cat. J Neurophysiol. 1983;50:910-25.

34. Clezy JK, Dennis BJ, Kerr DI. A degeneration study of the somaesthetic afferent systems in the marsupial phalanger, Trichosurus vulpecula. Aust J Exp Biol Med Sci. 1961;39:19-27.

35. Coghill RC, Talbot JD, Evans AC, Meyer E, Gjedde A, Bushnell C, Duncan GH Distributed processing of pain and vibration in the human brain. J Neurosci. 1994, 14: 4095-410

36. Coghill RC, Sang CN, Maisog JM, Iadarola MJ. Pain intensity processing within the human brain: a bilateral, distributed mechanism. J Neurophysiol 1999;82: 1934-1943

37. Cole J, Bushnell MC, McGlone F, Elam M, Lamarre Y, Vallbo A, Olausson H. Unmyelinated tactile afferents underpin detection of low-force monofilaments. Muscle Nerve. 2006;34: 105-7.

38. Coq JO, Qi H, Collins CE, Kaas JH. Anatomical and functional organization of somatosensory areas of the lateral fissure of the New World titi monkey (Callicebus moloch). J Comp Neurol. ;476:363-87. 
39. Craig AD. Supraspinal projections of lamina I neurons; In: Besson JM, Guilbaud G, Ollat H: Forebrain areas involved in pain processing; John Libbey Eurotext, Paris 1995.

40. Craig AD. How do you feel? Interoception: the sense of the physiological condition of the body. Nat Rev Neurosci. 2002;3:655-66.

41. Craig AD. Pain mechanisms: labeled lines versus convergence in central processing. Annu Rev Neurosci 2003; 26:1-30.

42. Craig AD. Distribution of trigeminothalamic and spinothalamic lamina I terminations in the macaque monkey. J Comp Neurol 2004a; 477:119 -148.

43. Craig AD. Lamina I, but not lamina V, spinothalamic neurons exhibit responses that correspond with burning pain. J Neurophysiol. 2004b;92:2604-9.

44. Craig AD. Retrograde analyses of spinothalamic projections in the macaque monkey: input to ventral posterior nuclei. J Comp Neurol. 2006; 499: 965-78.

45. Craig AD, Chen K, Bandy D, Reiman EM. Thermosensory activation of insular cortex. Nat Neurosci. 2000;3:184-90.

46. Darsow U, Drzezga A, Frisch M, Munz F, Weilke F, Bartenstein P, Schwaiger M, Ring J. Processing of histamine-induced itch in the human cerebral cortex: a correlation analysis with dermal reactions. J Invest Dermatol 2000;115:1029-33.

47. Davidson S, Zhang X, Yoon CH, Khasabov SG, Simone DA, Giesler GJ Jr. The itchproducing agents histamine and cowhage activate separate populations of primate spinothalamic tract neurons. J Neurosci 2007;27:1007-14.

48. Davidson S, Giesler GJ. The multiple pathways for itch and their interactions with pain. Trends Neurosci 2010;33:550-8.

49. De Balzac H. The Lily on the valley, 1836 (Le Lys dans la Vallée, translation KP Wormeley, Chapter 2).

50. Dejerine J, Mouzon J. Un nouveau type de syndrome sensitif cortical observé dans un cas de monoplégie corticale dissociée. Rev Neurol. 1915;2:1265-1273

51. Desmedt JE, Ozaki I. SEPs to finger joint input lack the N20-P20 response that is evoked by tactile inputs: contrast between cortical generators in areas $3 \mathrm{~b}$ and 2 in humans. Electroencephalogr Clin Neurophysiol 1991;80:513-21.

52. Disbrow E, Roberts T, Krubitzer L. Somatotopic organization of cortical fields in the lateral sulcus of Homo sapiens: evidence for SII and PV. J Comp Neurol. 2000; 418:1--21. 
53. Djouhri L, Lawson SN. Abeta-fiber nociceptive primary afferent neurons: a review of incidence and properties in relation to other afferent A-fiber neurons in mammals. Brain Res Brain Res Rev. 2004;46:131-45.

54. Dum RP, Levinthal DJ, Strick PL. The spinothalamic system targets motor and sensory areas in the cerebral cortex of monkeys. J Neurosci 2009;29:14223-35.

55. Dykes RW, Sur M, Merzenich MM, Kaas JH, Nelson RJ. Regional segregation of neurons responding to quickly adapting, slowly adapting, deep and Pacinian receptors within thalamic ventroposterior lateral and ventroposterior inferior nuclei in the squirrel monkey (Saimiri sciureus). Neuroscience. 1981;6:1687-92.

56. Drzezga A, Darsow U, Treede R-D, Siebner H, Frisch M, Munz F, Weilke F, Ring J, Schwaiger $\mathrm{M}$, and Bartenstein P. Central activation by histamine-induced itch: analogies to pain processing: a correlational analysis of O-15 H2O positron emission tomography studies. Pain 2001;92:295-305

57. Eickhoff SB, Schleicher A, Zilles K, Amunts K. The human parietal operculum. I. Cytoarchitectonic mapping of subdivisions. Cereb Cortex 2006a;16:254-67.

58. Eickhoff SB, Amunts K, Mohlberg H, Zilles K. The human parietal operculum. II. Stereotaxic maps and correlation with functional imaging results. Cereb Cortex 2006b;16:268-79.

59. Eickhoff SB, Grefkes C, Zilles K, Fink GR. The somatotopic organization of cytoarchitectonic areas on the human parietal operculum. Cereb Cortex 2007;17:1800-11.

60. Eisenberger NI, Lieberman MD. Why rejection hurts: a common neural alarm system for physical and social pain. Trends Cogn Sci. 2004; 8:294-300.

61. Fried I, Katz A, McCarthy G, Sass KJ, Williamson P, Spencer SS, Spencer DD. Functional organization of human supplementary motor cortex studied by electrical stimulation. J Neurosci 1991; 11: 3656-66.

62. Friedman DP, Murray EA. Thalamic connectivity of the second somatosensory area and neighboring somatosensory fields of the lateral sulcus of the macaque. J Comp Neurol 1986; $252: 348-373$.

63. Friedman DP, Murray EA, O'Neill JB, Mishkin M. Cortical connections of the somatosensory fields of the lateral sulcus of macaques: evidence for a corticolimbic pathway for touch. J Comp Neurol. 1986;252:323-47. 
64. Frot M, Rambaud L, Guenot M, Mauguiere F. Intracortical recordings of early pain-related CO2-laser evoked potentials in the human second somatosensory (S2) area. Clin Neurophysiol. 1999; 110: 133-45.

65. Frot M, Magnin M, Mauguiere F, Garcia-Larrea L. Human S2 and posterior insula differently encode thermal laser stimuli. Cereb Cortex, 2007, 17: 610-20.

66. Frot M, Mauguiere F, Magnin M, Garcia-Larrea L. Parallel processing of nociceptive A-delta inputs in S2 and midcingulate cortex in humans. J Neurosci, 2008, 28: 944-52.

67. Furlong PL, Aziz Q, Singh KD, Thompson DG, Hobson A, Harding GF. Cortical localisation of magnetic fields evoked by oesophageal distension. Electroencephalogr Clin Neurophysiol. 1998;108:234-43.

68. Gallay DS, Gallay MN, Jeanmonod D, Rouiller EM, Morel A. The Insula of Reil Revisited: Multiarchitectonic Organization in Macaque Monkeys. Cerebral Cortex 2012;22:175-90

69. Garcia-Larrea L. Insights gained into pain processing from patients with focal brain lesions. Neurosci Lett. 2012, in press (http://dx.doi.org/10.1016/j.neulet.2012.05.007)

70. Garcia-Larrea L, Frot M, Valeriani M. Brain generators of laser-evoked potentials: from dipoles to functional significance. Neurophysiol Clin. 2003; 33: 279-92.

71. Garcia-Larrea L, Perchet C, Creac'h C, Convers P, Peyron R, Laurent B, Mauguière F, Magnin M. Operculo-insular pain (parasylvian pain): a distinct central pain syndrome. Brain. 2010; 133: 2528-39.

72. Garraghty PE, Florence SL, Tenhula WN, Kaas JH. Parallel thalamic activation of the first and second somatosensory areas in prosimian primates and tree shrews. J Comp Neurol 1991;311:28999

73. Gingold SI, Greenspan JD, Apkarian AV. Anatomic evidence of nociceptive inputs to primary somatosensory cortex: relationship between spinothalamic terminals and thalamocortical cells in squirrel monkeys. J Comp Neurol. 1991;308:467-90.

74. Graziano A \& Jones EG. Widespread Thalamic Terminations of Fibers Arising in the Superficial Medullary Dorsal Horn of Monkeys and Their Relation to Calbindin Immunoreactivity. J Neurosci 2004; 24: 248-256.

75. Greenspan JD, Winfield JA.Reversible pain and tactile deficits associated with a cerebral tumor compressing the posterior insula and parietal operculum. Pain. 1992; 50: 29-39. 
76. Greenspan JD, Lee RR, Lenz FA. Pain sensitivity alterations as a function of lesion location in the parasylvian cortex. Pain. 1999; 81: 273-82.

77. Herde L, Forster C, Strupf M, Handwerker HO. Itch induced by a novel method leads to limbic deactivations a functional MRI study. J Neurophysiol. 2007;98:2347-56.

78. Hsieh JS, Hagermark O, Stahlebackdahl M, Ericson K, Eriksson L, Stoneelander S, Ingvar M. Urge to scratch represented in the human cerebral cortex during itch. J Neurophysiol 1994; 72:3004-3008

79. Horiuchi T, Unoki T, Yokoh A, Kobayashi S, Hongo K. Pure sensory stroke caused by cortical infarction associated with the secondary somatosensory area. J Neurol Neurosurg Psychiatry. 1996; 60: 588-9.

80. Hua LH, Strigo IA, Baxter L, Johnson SC, Craig AD. Anteroposterior somatotopy of innocuous cooling activation focus in human dorsal posterior insular cortex. Am J Physiol Regul Integr Comp Physiol 2005; 289: R319-R325.

81. Iannetti GD, Hughes NP, Lee MC, Mouraux A. Determinants of laser-evoked EEG responses: pain perception or stimulus saliency? J Neurophysiol. 2008;100:815-28.

82. Iannetti GD, Mouraux A. From the neuromatrix to the pain matrix (and back). Exp Brain Res. 2010; 205:1-12..

83. Indo Y. Nerve growth factor, pain, itch and inflammation: lessons from congenital insensitivity to pain with anhidrosis. Expert Rev Neurother. 2010;10:1707-24.

84. Isnard J, Guénot M, Sindou M, Mauguière F. Clinical manifestations of insular lobe seizures: a stereo-electroencephalographic study. Epilepsia 2004;45:1079-90.

85. Isnard J, Magnin M, Jung J, Mauguière F, Garcia-Larrea L. Does the insula tell the brain that we are in pain? Pain 2011;152:946-951

86. Jänig W. Neurobiology of visceral afferent neurons: neuroanatomy, functions, organ regulations and sensations. Biol Psychol 1996;42:29-51.

87. Jänig W, Morrison JF. Functional properties of spinal visceral afferents supplying abdominal and pelvic organs, with special emphasis on visceral nociception. Prog Brain Res. 1986;67:87-114.

88. Jeffry J, Kim S, Chen ZF. Itch signaling in the nervous system. Physiology (Bethesda). 2011;26:286-92.

89. Jones EG. Distribution patterns of individual medial lemniscal axons in the ventrobasal complex of the monkey thalamus. J Comp Neurol. 1983;215:1-16. 
90. Jones AKP, Friston K, Frakowiak RS. Localization of responses to pain in human cerebral cortex. Science 1992; 255: 215-216

91. Johnson JI, Kirsch JA, Reep RL, Switzer RC 3rd. Phylogeny through brain traits: more characters for the analysis of mammalian evolution. Brain Behav Evol. 1994;43:319-47.

92. Kaas JH. The evolution of isocortex. Brain Behav Evol. 1995;46:187-96.

93. Kaas JH, Collins CE. The organization of somatosensory cortex in anthropoid primates. Adv Neurol. 2003;93:57-67.

94. Kaas JH. Evolution of somatosensory and motor cortex in primates. Anat Rec A Discov Mol Cell Evol Biol. 2004;281:1148-56.

95. Kakigi R, Inui K, Tamura Y. Electrophysiological studies on human pain perception. Clin Neurophysiol. 2005;116:743-63.

96. Kenshalo DR Jr, Giesler GJ Jr, Leonard RB, Willis WD. Responses of neurons in primate ventral posterior lateral nucleus to noxious stimuli. J Neurophysiol. 1980;43:1594-614.

97. Kevetter GA, Willis WD. Collateralization in the spinothalamic tract: new methodology to support or deny phylogenetic theories. Brain Res 1984;319:1-14.

98. Kim JS. Pure sensory stroke. Clinical-radiological correlates of 21 cases. Stroke 1992; 23: 9837.

99. Kim JS. Patterns of sensory abnormality in cortical stroke: evidence for a dichotomized sensory system. Neurology 2007; 68: 174-80.

100.Kross E, Berman MG, Mischel W, Smith EE, Wager TD. Social rejection shares somatosensory representations with physical pain. Proc Natl Acad Sci U S A. 2011;108:6270-5.

101.Krubitzer LA, Kaas JH. The organization and connections of somatosensory cortex in marmosets. J Neurosci. 1990;10:952-74.

102.Krubitzer LA, Calford MB. Five topographically organized fields in the somatosensory cortex of the flying fox: microelectrode maps, myeloarchitecture, and cortical modules. J Comp Neurol. 1992; 317:1-30.

103.Krubitzer L, Clarey J, Tweedale R, Elston G, Calford M. A redefinition of somatosensory areas in the lateral sulcus of macaque monkeys. J Neurosci. 1995;15:3821-39. 
104.Kutoku Y, Hagiwara H, Ichikawa Y, Takeda K, Sunada Y. A case of combined sensation disturbance and clumsiness of the left hand caused by an infarction localized to Brodmann areas 1 and 2. Rinsho Shinkeigaku. 2007; 47: 151-5.

105.Legrain V, Iannetti GD, Plaghki L, Mouraux A. The pain matrix reloaded A salience detection system for the body. Prog Neurobiol. 2010; 93:111-24

106.Leknes SG, Bantick S, Willis CM, Wilkinson JD, Wise RG, Tracey I. Itch and motivation to scratch: an investigation of the central and peripheral correlates of allergen- and histamine-induced itch in humans. J Neurophysiol. 2007;97:415-22.

107.Lenz FA, Seike M, Lin YC, Baker FH, Rowland LH, Gracely RH, Richardson RT. Neurons in the area of human thalamic nucleus ventralis caudalis respond to painful heat stimuli. Brain Research 1993, 623: 235-240

108.Lenz FA, Gracely RH, Rowaland LH, Dougherty PM. A population of cells in the human thalamic principal sensory nucleus respond to painful mechanical stimuli. Neurosci. lett. 1994, 180 : $46-50$

109.Lenz FA, Gracely RH, Romanoski AJ, Hope EJ, Rowaland LH, Dougherty PM. Stimulation in the human somatosensory thalamus can reproduce both the affective and sensory dimensions of previously experienced pain. Nature Medicine 1995; 1: 910-91

110.Lenz FA, Rios M, Chau D, Krauss GL, Zirh TA, Lesser RP. Painful stimuli evoke potentials recorded from the parasylvian cortex in humans. J Neurophysiol 1998;80:2077-88.

111.Lenz FA, Ohara S, Gracely RH, Dougherty PM, Patel SH. Pain encoding in the human forebrain: binary and analog exteroceptive channels. J Neurosci. 2004; 24:6540-4.

112.Löken LS, Evert M, Wessberg J. Pleasantness of touch in human glabrous and hairy skin: order effects on affective ratings. Brain Res. 2012;1417:9-15.

113.Lorenz J, Garcia-Larrea L. Contribution of attentional and cognitive factors to laser evoked brain potentials. Neurophysiol Clin 2003; 33: 293-301.

114.Lu CL, Wu YT, Yeh TC, Chen LF, Chang FY, Lee SD, Ho LT, Hsieh JC. Neuronal correlates of gastric pain induced by fundus distension: a 3T-fMRI study. Neurogastroenterol Motil. 2004;16:575-87.

115.Macdonald G, Leary MR. Why does social exclusion hurt? The relationship between social and physical pain. Psychol Bull. 2005;131(2):202-23. 
116.Maihofner C, Kaltenhauser M, Neundorfer B, Lang E. Temporo-spatial analysis of cortical activation by phasic innocuous and noxious cold stimuli--a magnetoencephalographic study. Pain 2002; 100: 281-90.

117.Mauguiere F, Desmedt JE. Thalamic pain syndrome of Dejerine-Roussy. Differentiation of four subtypes assisted by somatosensory evoked potentials data. Arch Neurol 1988; 45: 1312-20.

118.Mazzola L, Isnard J, Mauguiere F. Somatosensory and pain responses to stimulation of the second somatosensory area (S2) in humans. A comparison with SI and insular responses. Cereb Cortex. 2006; 16:960-8.

119.Mazzola L, Isnard J, Peyron R, Guénot M, Mauguière F. Somatotopic organization of pain responses to direct electrical stimulation of the human insular cortex. Pain. 2009; 146:99-104.

120.Mazzola L, Isnard J, Peyron R, Mauguière F. Stimulation of the human cortex and the experience of Pain: Wilder Penfield's observations revisited. Brain 2012; 135:631-40.

121. Mazzola L, Faillenot I, Barral FG, Mauguière F, Peyron R. Spatial segregation of somatosensory and pain activations in the human operculo-insular cortex. Neuroimage. 2012; 60:409-18

122. Mayer EA, Aziz Q, Coen S, Kern M, Labus JS, Lane R, Kuo B, Naliboff B, Tracey I. Brain imaging approaches to the study of functional GI disorders: a Rome working team report. Neurogastroenterol Motil. 2009;21:579-96.

123.Mendell JR, Sahenk Z. Clinical practice. Painful sensory neuropathy. N Engl J Med. 2003; 348: 1243-55.

124.McHaffie JG, Kruger L, Clemo HR, Stein BE. Corticothalamic and corticotectal somatosensory projections from the anterior ectosylvian sulcus (SIV cortex) in neonatal cats: an anatomical demonstration with HRP and 3H-leucine. J Comp Neurol. 1988;274:115-26.

125.McKeefry DJ, Burton MP, Vakrou C, Barrett BT, Morland AB. Induced deficits in speed perception by transcranial magnetic stimulation of human cortical areas V5/MT+ and V3A. J Neurosci. 2008;28:6848-57.

126.Mehler WR. The anatomy of the so-called "pain tract" in man. An analysis of the course and distribution of the ascending fibers of the fasciculus anterolateralis. In: Basic research in paraplegia, Ed by John D French and Robert W Porter, Charles C Thomas Publisher, Springfield, Ill, USA, 1962, pp. 26-55.

127. Mehler WR. Some neurological species differences -a posteriori. Ann NY Acad Sci 1969; 167 (Comparative and Evolutionary Aspects of the Vertebrate Central Nervous System): 424-468 
128.Mesulam MM, Mufson EJ. Insula of the old world monkey. III: Efferent cortical output and comments on function. J Comp Neurol. 1982;212:38-52.

129.Mochizuki H, Tashiro M, Kano M, Sakurada Y, Itoh M, Yanai K. Imaging of central itch modulation in the human brain using positron emission tomography. Pain 2003;105:339-46.

130.Mochizuki H, Sadato N, Saito DN, Toyoda H, Tashiro M, Okamura N, Yanai K. Neural correlates of perceptual difference between itching and pain: a human fMRI study. Neuroimage 2007;36:706-17.

131.Mochizuki H, Inui K, Yamashiro K, Ootsuru N, Kakigi R. Itching-related somatosensory evoked potentials. Pain 2008;138:598-603.

132. Mochizuki H, Inui K, Tanabe HC, Akiyama LF, Otsuru N, Yamashiro K, Sasaki A, Nakata H, Sadato N, Kakigi R. Time course of activity in itch-related brain regions: a combined MEG-fMRI study. J Neurophysiol. 2009;102:2657-66.

133.Morrison I, Löken LS, Minde J, Wessberg J, Perini I, Nennesmo I, Olausson H. Reduced Cafferent fibre density affects perceived pleasantness and empathy for touch. Brain. 2011;134:111626.

134.Mountcastle VS. “The sensory hand”, Harvard Unive Press, 2005.

135.Mufson EJ, Mesulam MM. Thalamic connections of the insula in the rhesus monkey and comments on the paralimbic connectivity of the medial pulvinar nucleus. J Comp Neurol 1984; 227:109-120.

136.Nathan PW. Touch and surgical division of the anterior quadrant of the spinal cord. J Neurol Neurosurg Psychiatry. 1990;53:935-9.

137.Nicholls JG, Baylor DA. Specific modalities and receptive fields of sensory neurons in CNS of the leech. J Neurophysiol. 1968;31:740-56.

138.Nieuwenhuys R The insular cortex: A review. In M. A. Hofman and D. Falk (Eds.) Progress in Brain Research, Vol. 195. Chapter 7, pp. 123-163.

139.Oaklander AL. Neuropathic itch. Semin Cutan Med Surg. 2011;30:87-92.

140.Obrador S, Dierssen G, Ceballos R. Consideraciones cli'nicas, neurolo' gicas y anato' micas sobre el llamado dolor talámico. Acta Neurologica Latinoamericana 1957; 3: 58-77.

141.Olausson H, Lamarre Y, Backlund H, Morin C, Wallin BG, Starck G, Ekholm S, Strigo I, Worsley K, Vallbo AB, Bushnell MC. Unmyelinated tactile afferents signal touch and project to insular cortex. Nat Neurosci 2002; 5:900-4. 
142. Olausson HW, Cole J, Vallbo A, McGlone F, Elam M, Krämer HH, Rylander K, Wessberg J, Bushnell MC. Unmyelinated tactile afferents have opposite effects on insular and somatosensory cortical processing. Neurosci Lett 2008;436:128-32.

143.Ostrowsky K, Magnin M, Ryvlin P, Isnard J, Guenot M, Mauguiere F. Representation of pain and somatic sensation in the human insula: a study of responses to direct electrical cortical stimulation. Cereb Cortex 2002; 12:376-85

144.Papoiu AD, Coghill RC, Kraft RA, Wang H, Yosipovitch G. A tale of two itches. Common features and notable differences in brain activation evoked by cowhage and histamine induced itch. Neuroimage 2012; 59:3611-23

145.Pastor J, Soria B, Belmonte C. Properties of the nociceptive neurons of the leech segmental ganglion. J Neurophysiol 1996;75:2268-2279

146.Penfield W, Jasper WW. Epilepsy and the functional anatomy of the human brain. Boston: Little, Brown; 1954

147.Pereira LC, Modesto AM, Sugai R, daMota LA. Pain sensitive cerebral areas and intracranial structures revealed at fully awake craniotomies for primary intracranial tumor resection. In: Abstracts, IASP 11th World Congress on Pain, vol. 1517. Seattle: IASP Press; 2005. p. 20.

148.Perl ER. Getting a line on pain: is it mediated by dedicated pathways? Nat Neurosci. 1998;1: $177-8$.

149.Peyron R, Garcia-Larrea L, Gregoire MC, Costes N, Convers P, Lavenne F, Mauguiere F, Michel D, Laurent B. Haemodynamic brain responses to acute pain in humans: sensory and attentional networks. Brain 1999;122:1765-80.

150.Peyron R, Laurent B, Garcia-Larrea L. Functional imaging of brain responses to pain. A review and meta-analysis. Neurophysiol Clin 2000;30:263-88

151.Pfaus JG, Kleopoulos SP, Mobbs CV, Gibbs RB, Pfaff DW (1993) Sexual stimulation activates c-fos within estrogen-concentrating regions of the female rat forebrain. Brain Res 624:253-267.

152.Pollin B, Albe-Fessard D. Organization of somatic thalamus in monkeys with and without section of dorsal spinal tracts. Brain Res. 1979;173:431-49.

153.Porro CA, Baraldi P, Pagnoni G, Serafini M, Facchin P, Maieron M, Nichelli P. Does anticipation of pain affect cortical nociceptive systems? J Neurosci. 2002;22:3206-14. 
154.Price CJ, Mummery CJ, Moore CJ, Frakowiak RS, Friston KJ. Delineating necessary and sufficient neural systems with functional imaging studies of neuropsychological patients. J Cogn Neurosci 1999; 11:371-82.

155.Qi HX, Lyon DC, Kaas JH. Cortical and thalamic connections of the parietal ventral somatosensory area in marmoset monkeys (Callithrix jacchus). J Comp Neurol. 2002; 443:168-182.

156.Ren Y, Zhang L, Lu Y, Yang H, Westlund KN. Central lateral thalamic neurons receive noxious visceral mechanical and chemical input in rats. J Neurophysiol. 2009;102:244-58.

157.Richer F, Martinez M, Robert M, Bouvier G, Saint-Hilaire JM. Stimulation of human somatosensory cortex: tactile and body displacement perceptions in medial regions. Exp Brain Res 1993;93:173-6.

158. Rinaman L. Ascending projections from the caudal visceral nucleus of the solitary tract to brain regions involved in food intake and energy expenditure. Brain Res. 2010;1350:18-34.

159.Ringkamp M, Schepers RJ, Shimada SG, Johanek LM, Hartke TV, Borzan J, Shim B, LaMotte RH, Meyer RA. A role for nociceptive, myelinated nerve fibers in itch sensation. J Neurosci 2011; 31:14841-9.

160.Robinson CJ, Burton H. Somatic sub-modality distribution within the second somatosensory (S2), 7b, retroinsular, postauditory, and granular insular cortical areas of $\mathrm{M}$. fascicularis. J Comp Neurol. 1980;192:93-108.

161.Roggendorf J, Vent J, Maarouf M, Haense C, Thiel A, Fink GR, Hilker R. [Reversible hypogeusia during bilateral thalamic stimulation for essential tremor]. Nervenarzt 2008;79:454-6.

162.Russo D, Paparcone R, Genovese A. A cytoarchitectonic and myeloarchitectonic study of the insular cortex of the bull, Bos taurus. Acta Histochem. 2008;110:245-55

163.Ruzzoli M, Gori S, Pavan A, Pirulli C, Marzi CA, Miniussi C. The neural basis of the Enigma illusion: A transcranial magnetic stimulation study. Neuropsychologia. 2011;49:3648-55.

164.Sanides F. Functional architecture of motor and sensory cortex in primates in the light of a new concept of cortical evolution. In : The Primate Brain, Nowack CR and Montagna W (Eds), Appelton-Century-Croft 1970, pp.137-208

165.Schmahmann JD, Leifer D. Parietal pseudothalamic pain syndrome: clinical features and anatomic correlates. Arch Neurol 1992; 49:1032-37. 
166.Schlereth T, Baumgärtner U, Magerl W, Stoeter P, Treede RD. Left-hemisphere dominance in early nociceptive processing in the human parasylvian cortex. Neuroimage. 2003; 20: 441-54.

167.Schneider RJ, Friedman DP, Mishkin M. A modality-specific somatosensory area within the insula of the rhesus monkey. Brain Res. 1993; 621:116--120.

168.Seo WK, Kwon DY, Seo SH, Park MH, Park KW. Neuropathic pruritus following Wallenberg syndrome. Neurology 2009;72:676.

169.Sherington CS. The Integrative Action of the Nervous System. New York, Charles Scribner's Sons, 1906

170.Shintani S. Clinical-radiologic correlations in pure sensory stroke. Neurology 1998; 51: 297302.

171.Siegel AM, Williamson PD, Roberts DW, Thadani VM, Darcey TM. Localized pain associated with seizures originating in the parietal lobe. Epilepsia. 1999; 40: 845-55.

172.Singer T, Seymour B, O'Doherty J, Kaube H, Dolan RJ, Frith CD. Empathy for pain involves the affective but not sensory components of pain. Science. 2004;303:1157-62.

173.Smith ES, Lewin GR. Nociceptors: a phylogenetic view. J Comp Physiol A Neuroethol Sens Neural Behav Physiol. 2009; 195:1089-106.

174.Sneddon LU. Pain perception in fish: indicators and endpoints. ILAR J. 2009;50:338-42.

175.Stein BE, Spencer RF, Edwards SB. Corticotectal and corticothalmic efferent projections of SIV somatosensory cortex in cat. J Neurophysiol 1983; 50:896-908.

176.Stephani C, Fernandez-Baca Vaca G, Maciunas R, Koubeissi M, Lüders HO. Functional neuroanatomy of the insular lobe. Brain Struct Funct. 2011;216:137-49.

177.Stephenson DT, Arneric SP. Neuroimaging of pain: advances and future prospects. J Pain. 2008;9:567-79.

178.Stevens RT, London SM, Apkarian AV. Spinothalamocortical projections to the secondary somatosensory cortex (SII) in squirrel monkey. Brain Res 1993;631:241-6

179.Talbot JD, Marrett S, Evans AC, Meyer E, Bushnell MC, Duncan GH. Multiple representations of pain in human cerebral cortex. Science 1991 15;251:1355-8

180.Tattersall JE, Cervero F, Lumb BM. Viscerosomatic neurons in the lower thoracic spinal cord of the cat: excitations and inhibitions evoked by splanchnic and somatic nerve volleys and by stimulation of brain stem nuclei. J Neurophysiol. 1986;56:1411-23. 
181.Tracey I, Mantyh PW. The cerebral signature for pain perception and its modulation. Neuron. 2007;55:377-91.

182.Tracey I. Imaging pain. Br J Anaesth. 2008;101:32-9.

183.Truitt WA, Shipley MT, Veening JG, Coolen LM. Activation of a subset of lumbar spinothalamic neurons after copulatory behavior in male but not female rats. $J$ Neurosci. 2003;23:325-31.

184.Valeriani M, Rambaud L, Mauguiere F. Scalp topography and dipolar source modelling of potentials evoked by CO2 laser stimulation of the hand. Electroencephal Clin Neurophysiol 1996; 100: $343-53$

185. Valet M, Sprenger T, Boecker H, Willoch F, Rummeny E, Conrad B, Erhard P, Tolle TR. Distraction modulates connectivity of the cingulo-frontal cortex and the midbrain during pain--an fMRI analysis. Pain 2004; 109:399-408.

186.Valet M, Sprenger T, Tölle TR. Studies on cerebral processing of pain using functional imaging: Somatosensory, emotional, cognitive, autonomic and motor aspects. Schmerz. 2010;24:114-21.

187.Vierow V, Fukuoka M, Ikoma A, Dörfler A, Handwerker HO, Forster C. Cerebral representation of the relief of itch by scratching. J Neurophysiol 2009;102:3216-24.

188. Walters ET, Byrne JH, Carew TJ, Kandel ER. Mechanoafferent neurons innervating tail of Aplysia. I. Response properties and synaptic connections. J Neurophysiol 1983; 50:1522-1542.

189. Wang JY, Chang JY, Woodward DJ, Luo F. Temporal strategy for discriminating noxious from non-noxious electrical stimuli by cortical and thalamic neural ensembles in rats. Neurosci Lett. 2008;435:163-8.

190.Willis, W.D. The Pain System (Karger, Basel, 1985).

191.Willis WD, Westlund KN. Neuroanatomy of the pain system and of the pathways that modulate pain. J Clin Neurophysiol. 1997;14:2-31.

192.Willis WD, AlChaer, E.D.; Quast, M.J;; Westlund, K.N. A visceral pain pathway in the dorsal column of the spinal cord. PNAS 1999; 96: 7675-7679

193.Willis WD, Zhang XJ, Honda CN, Giesler GJ (2002) A critical review of the role of the proposed VMpo nucleus in pain. J Pain 3:79-94

194.Wirth FP. Insular-diencephalic connections in the Macaque. J Comp Neurol. 1973; 150: 36192. 
195.Wu CW, Bichot NP, Kaas JH. Somatosensory areas S2 and PV project to the superior colliculus of a prosimian primate, Galago garnetti. Somatosens Mot Res. 2005;22:221-31.

196.Yosipovitch G, Ishiuji Y, Patel TS, Hicks MI, Oshiro Y, Kraft RA, Winnicki E, Coghill RC. The brain processing of scratching. J Invest Dermatol 2008;128:1806-11.

197.Zeki S, Watson JD, Frackowiak RS. Going beyond the information given: the relation of illusory visual motion to brain activity. Proc Biol Sci. 1993;252: 215-22.

198.Zhang DX, Owens CM, Willis WD. Intracellular study of electrophysiological features of primate spinothalamic tract neurons and their responses to afferent inputs. J Neurophysiol. 1991;65:1554-66.

199.Zhang HQ, Murray GM, Turman AB, Mackie PD, Coleman GT, Rowe MJ. Parallel processing in cerebral cortex of the marmoset monkey: effect of reversible SI inactivation on tactile responses in SII. J Neurophysiol 1996;76:3633-55

200.Zhang ZH, Dougherty PM, Oppenheimer SM. Characterization of baroreceptor-related neurons in the monkey insular cortex. Brain Res. 1998;796:303-6.

201.Zhang ZH, Dougherty PM, Oppenheimer SM. Monkey insular cortex neurons respond to baroreceptive and somatosensory convergent inputs. Neuroscience. 1999;94:351-60.

\section{Figure legends}

Figure 1. The medial operculum - posterior insula contains nociceptive-specific networks. A. Intracortical evoked potentials to thermo-nociceptive (laser) stimuli recorded from the inner opercular area. Increasing the stimulus intensity enhances the amplitude of responses, which are visible at sensory threshold (ST), increase till reaching pain threshold (PT) but do not change much between pain threshold and supra-threshold levels (upper traces) (Modified from Frot et al 2007). B. Points of intracortical opercular-insular stimulation giving rise (red) or not giving rise (white) to a subjective painful sensation. Most of the points evoking pain are concentrated in the dorsal posterior insula. (Modified from Mazzola et al 2006). C. Focal lesions entailing a selective suppression of pain 
sensations in the opposite side of the body, with preserved proprioception. Lesions involve the posterior insula and medial operculum (two left scans from Garcia-Larrea et al 2010; right frame from Greenspan et al 1999). D. Diagram representing in color-code the brain regions where focal lesions gave rise to central neuropathic pain with alteration of pain sensitivity. The area where all lesions converge covers the posterior insular - medial opercular cortex (PIMO). From Garcia-Larrea et al 2010. All references by permission.

Figure 2. Differential encoding of noxious and non-noxious thermal stimuli in the PIMO. (A -left panel) Operculo-insular sites evoking pain and thermal perceptions in humans. Upper part: axial slices; lower part: coronal slices. Sites where stimulation induced non-noxious thermal sensations (in green) were situated more laterally, in the inner operculum, while those evoking pain (in red) tended to concentrate more medially, in the posterior insula (adapted from Mazzola et al Pain 2006). B (right panel). Intracortical evoked potentials to thermal laser stimuli recorded from the posterior insula (black squares) and the inner operculum (black crosses). In the lower part, responses from 8 consecutive subjects are superimposed. Sizeable responses at low intensities (sensory threshold) could be obtained from opercular sites (left), but not from the insula (right), which only responded when intensity almost reached the subjective pain threshold. (Adapted from Frot et al, Cereb Cortex 2007). All references by permission. 